\title{
Large Energy Projects and Community Benefits Agreements - some experience from the UK
}

\begin{abstract}
Large projects are often controversial projects, with wide ranging implications for host localities. Energy projects, including windfarms, nuclear power stations, and the more recent cases of fracking and nuclear waste geological disposal, provide particularly high profile cases. In response to concern there has been the emergence of a whole family of new procedures, processes and methods for their assessment and management, including the advent of Community Benefit Agreements (CBAs). This article examines some of the critical issues around the increasing use of such agreements, including: their justification, relationship to the planning process, scale of benefits (which can be very large), types of benefits, and their management and distribution. The focus is on emerging UK practice in relation to energy projects, but there will also be reference to some relevant practice elsewhere-especially in the EU and North America.
\end{abstract}

Key words: Community Benefits Agreements, UK energy projects

\section{Large energy projects in context}

The progress or otherwise of big projects, and their associated impacts, tend to be headline news topics in many countries. Such projects can include manufacturing, services and especially infrastructure activities and these often involve special decision making procedures. For example, in the UK, the 2008 Planning Act identifies a set of Nationally Significant Infrastructure Projects (NSIPs) in the fields of energy, transport, water, waste water and waste (HMG 2008). The projects vary in size; some are 'mega projects' costing billions, covering large areas, employing many thousands of people usually in construction, and invariably controversial. These are often the sort of projects for which the acronym LULU (locally unacceptable land uses) was coined several decades ago in the USA. The projects have wide-ranging impacts, both bio-physical and socio-economic.

To address such impacts, we have witnessed the evolution of a whole family of procedures, processes and methods of assessment and-management. These include of course the widening impact assessment (IA) family-EIA/SIA/SEA/SA/HIA/HRA/EqIA1and many others. They sometimes include special procedures for subsets of major projects, as noted in the UK above, with a project examination system operated by the National Infrastructure Division of the Planning Inspectorate (PINS). PINS provides a 
good set of guidance documents on aspects of the planning and assessment process for major projects (PINS, 2012-2017). They may also include special arrangements for potential major project host authorities, such as the UK Planning Performance Agreements (PPAs), through which the developer provides often substantial funding to enable host local authorities to better critically assess the potential local impacts of the project (DCLG 2015).

There are also Community Benefit Agreements (CBAs) ${ }^{2}$. The term refers to those agreements between the various stakeholders involved in a project, in particular between the developer and the host community, which can provide a range of benefits, including financial incentives, infrastructure, and community empowerment measures. In many respects it is synonymous with the term Community Benefit Schemes, which is also used in practice. There are various arguments for CBAs, most recently that they are offered not to compensate for projected impacts, but in recognition of the community's participation in an activity that is perceived as being 'in the national interest'. Additionally for many large projects there are always likely to be some indirect disturbance effects and changes in lifestyle which are less easy to address directly. CBAs are becoming a growing element in the assessment and development of major projects, especially energy projects, in the UK and internationally.

The aim of this article is to explore the evolving nature of CBAs, and the issues they raise with particular reference to contemporary energy projects in the UK. These projects include large windfarms (on-shore and off-shore), gas fired power stations, a new generation of nuclear power stations, plus the associated search for a nuclear waste geological disposal facility, and fracking for shale gas. The focus on energy projects, primarily in the UK, reflects the substantial activity on such projects in recent years; many of the projects are controversial. There has also been a diverse and evolving experience of the use of CBAs, from early use in on-shore wind farm projects to contemporary proposals for major nuclear power projects and the storage of nuclear waste. The article employs a number of analytical lenses: (1) an evolutionary lens reviewing changes in the use of CBAs for large energy projects in the UK over approximately the last 15 years; (2) a wide-angled lens exploring a broader range of energy technologies, and cross-technology comparisons, from the early use of CBAs for onshore wind farms, plus early work on the management of radioactive waste, to the application to a much wider range of energy projects; and (3) a limited international lens drawing on some comparative experiences from a number of other countries.

The article builds from a core of relevant research and practice particularly in relation to community benefits and on-shore wind projects (see in particular CSE 2005, 2007; Walker and Cass 2007; Aitken 2010; Cowell, Bristow and Munday 2011), and to community benefits and the management of radioactive waste (see in particular COWAM 2009, Argona 2010, Richardson 2010). It adds further findings from more recent CBA research across the various energy technologies, plus material from 
practice from particular energy developments and industry groups, and from the evolving local and national policy contexts. It seeks to explore the evolving nature of Community Benefit Agreements in relation to a number of key issues.

After an outline of the employed research approach (section 2), the following sections (3-7) explore some key issues associated with the use of CBAs. This starts with an examination of the justification for such measures, and a consideration of potential confusion of role in relation to project mitigation measures. Once the justification has been established for a CBA in relation to a particular project, a whole raft of $C B A$ operational issues follow. What constitutes a fair and reasonable scale of community benefits, over what period of time, in relation to a particular project? What types of benefits are possible? Who controls CBAs, and how are they managed in practice? How are benefits to be distributed -- to whom and when? Scale issues are controversial, encompassing conflicting and increasingly rising expectations, plus issues of consistency and comparison within and between energy project types. The nature of possible benefits is widening from an initial focus on financial incentives and infrastructure to an inclusion of more social and community empowerment measures. Distributional issues can also be controversial; who decides and what are the operational criteria for distribution? For example what are the roles of the developer and local agencies in managing the process; what is the distributional balance between the local and wider regional communities? The article seeks to explore the key CBA issues across the various energy sub-sectors, across larger and smaller projects, exploring areas of cross relevance, of similarities and differences.

There is a focus on evolving practice in the UK energy sector and its sub-sectors. The aim is to highlight good practice where appropriate, but also to note some fuzzy and contentious areas. Where applicable, there is also reference to some international comparative experience on the CBA issue, noting in particular EU experience, but also considering practice elsewhere, for example in North America. The final section (8) considers the future role of CBAs, their significance especially for major project developments, but also the importance of handling with care some of the key issues raised here.

\section{Research approach: scoping the range of contemporary UK major energy projects and CBAs}

The article draws on several approaches to the scoping of the range of relevant UK energy related projects and community benefit agreements. A Google search of key words over the period 2001 to mid-2016 sets the wider range to the scoping exercise. This is reinforced by the author's own knowledge of relevant projects drawing on academic and consultancy work on major energy projects in the UK and overseas over 
the last 30 years. A final and contemporary sieve is provided by an examination of those major energy projects which have been examined under the national infrastructure regime established by the 2008 Planning Act. In all cases there is a focus on those projects which have been completed, or are under construction, or have been approved for development. Whilst the article does not claim to include coverage of all large energy projects in the UK over the last 15 years, it does aim to identify from the range of cases considered some emerging trends across the energy sector and its sub-sectors. This project focus is complemented by an examination of relevant local and national government and/or industry policy and guidance on community benefits for energy projects.

The Google search on 'UK energy projects and community benefit agreements' emphasises the predominance of work in the on-shore wind energy industry, and especially in Scotland. Other energy sectors are minor in comparison, with some limited mention of off-shore wind, solar farm projects, and nuclear. A more targeted search on particular energy sub-sectors notes nuclear, especially Hinkley Point $C$, and evolving policy around nuclear waste disposal and fracking. There is little or no mention of CBAs for fossil-fuelled plants, including the burgeoning array of Combined Cycle Gas Turbine (CCGT) projects in the UK, which is a little surprising given that such projects are generally seen as less environmentally benign than renewables.

The search of energy projects under the 2008 national infrastructure regime (PINS website at September 2016) revealed, of the 38 decided projects, a preponderance of large off-shore wind farms, especially in the North Sea, several CCGT plants, and various grid/pipeline projects. On-shore windfarms are limited to a few projects in Wales; there is also Hinkley Point $C$ nuclear, Swansea Bay tidal, and a biomass project. The explicit CBA content in the documentation of these projects is limited; partly as such content is not a material consideration in the planning process. However, outwith the planning applications and decisions on these projects, there is some evidence of an increasing role for CBAs, especially for large off-shore wind farms, although this is still limited compared to the previously noted content on on-shore wind farms, especially in Scotland. Again there is little of note for CCGT projects, perhaps reflecting that the development of such projects in the UK has been less locally contentious.

\section{Justification for CBAs}

What is the justification for having CBAs at all? Views can be typified between the extremes of the altruistic where developer philanthropy meets community interests to the cynical and highly sceptical of CBAs as developer bribes to effectively buy a planning consent. Views also vary between different national contexts. Advocated reasons for CBAs have also evolved over time. Views on justification can also vary 
substantially between stakeholders involved in particular projects. Developers prefer to talk much more about positive motives, being a good neighbour and corporate social responsibility rather than paying compensation (Cass et al 2010).

Overall this is quite a fuzzy area, with overlapping motives including for example: being good neighbours, sharing rewards, supporting community engagement, providing compensation, and delivering fair reparations. Cowell et al (2011) talk of 'constructive ambiguity' in relation to their study of on-shore wind farms in Wales, 'in which fluidity of meaning allows the concept to hold together a range of interests'. In addition, there has been an overlapping of CBA roles in some cases with what one might expect to be covered through the normal planning and environmental assessment and decision making process.

\section{Evolving and varied international context}

The USA was an early pioneer and provides examples of quite a wide definition and rationale for CBAs in relation to a range of project types, much wider than energy projects. For example Gross et al (2002) defines a CBA as:

---a legally enforceable contract, signed by community groups and by a developer, setting forth a range of community benefits that the developer agrees to provide as part of a development project. A CBA is the result of a negotiation process between the developer and organised representatives of affected communities, in which the developer agrees to shape the development in a certain way or to provide specified community benefits. In exchange, the community group promises to support the proposed project before government bodies that provide the necessary permits and subsidies. The CBA is both a process to work towards these mutually beneficial objectives, and a mechanism to enforce both sides' promises.

In similar vein, Baxamusa (2008) defines a CBA as:

-- a private agreement between a community coalition and the developer on multiple issues that may or may not be included in the regular planning process. The CBA is different from other private agreements in that it is between a developer and a coalition of multiple community groups with plural interests.

Here CBAs are seen as valuable in shifting the traditional antagonistic relationship between developer and public towards a more deliberative relationship. Their use has spread across the USA in the last 10 years or so - from the initial pioneering Los Angeles' examples (eg Lakers stadium/LA, Los Angeles Airport Expansion (LAX)) (Baxamusa 2008) to major energy projects (see for example the CBA for Salem Harbor CCGT project, City of Salem 2014). But it can be argued that in many US cases CBAs are substituting for measures which should be normal mitigation and/or enhancement measures for major projects, and are distorting the planning system. For example, of the $\$ 500 \mathrm{~m}$ community benefits for LAX expansion, $\$ 230 \mathrm{~m}$ was for soundproofing local 
schools and homes. Been (2010) compiles a valuable legal and policy critique of the evolving US approach concluding, inter alia, that 'local governments should reject any considerations of CBAs in the land use approval process or recognise only those CBAs that meet both substantive and procedural standards designed to limit their potential threats'.

Elsewhere, and especially for energy projects, Denmark provides an example of where the government has taken steps to provide subsidies to those local areas which take renewable projects where the positive external benefits accrue on a national or global rather than local stage (Cass et al2010). France has used community benefits over several decades as a form of compensation in relation to its Grand Chantiers programme, in particular in relation to the EDF nuclear power station programme. The alleged level of CBA funding for local communities varies from $1 \%-10 \%$ of project value, for a wide range of activities, and especially for affordable housing. In relation to the other end of the nuclear power cycle, the EU's COWAM research programme on the management of radioactive waste has produced some valuable findings on the use of community benefits and support packages (COWAM 2009). The research findings note that:

All around the world an important safeguard generally offered to potential host communities (however such a community is defined) is that the community should not find itself worse off than before the process to site a radioactive waste management facility began. This in turn led to the development of a number of so-called 'impact mitigation' measures. Not least amongst these has been the offering of specific benefits packages to the community, by way of compensation, not necessarily for bearing an increased risk, but simply for allowing itself to be considered. It is now generally the case that such benefits comprise a mixture of the purely financial and measures designed to assist the community to take part and ensure enhanced well-being beyond the lifetime of the facility in question.

There is increasing evidence that benefit packages are being designed as integrated development instruments intended to not only support a community during the initial stages and through facility operation, but also into the long-term future, with special reference to the welfare of future generations.

Some UK energy project experience

The wind energy industry has been at the forefront in the development of community benefits agreements in the UK. A 2007 report on the topic (Centre for Sustainable Energy, 2007), outlined a range of justifications for such benefits, including: being a good neighbour in terms of engaging with the host community; paying compensation for impacts on local amenity and the inconvenience caused by the construction process; and sharing the rewards from wind as a 'common' which nobody owns. The report also 
noted that, unlike housing, wind energy leaves little in the way of specific benefit for the locality in which it is based. More recent best practice guidance for English wind farms noted that community benefits are 'an important way of sharing the value that wind energy can bring with the local community' (Department of Energy and Climate Change (DECC) 2014a). Specifically in relation to Welsh wind farms, and Welsh energy policy, Cowell et al (2011) identify an important liability motive, 'fairness requires that some form of reparations benefit is offered to communities affected by developments which are justified on a wider public interest basis.'

An early example of a small scale community benefits agreement in another energy sub-sector was one in relation to the construction of the Sizewell B nuclear power station, completed in 1995, and still the most recent UK nuclear new build. This constituted a package of 'ameliorative measures', including many village hall improvement projects, in general recognition of the pressure placed on local facilities by the project (Glasson 2005). More recently the proposal for the new Hinkley Point $C$ nuclear plant has been accompanied by a much more substantial CBA, as will be discussed in a subsequent section. At the time the responsible Minister, Michael Fallon, commented that 'It is absolutely essential that we recognise the contributions of those communities that host major new energy projects' (DECC 2016).

Again recently, in relation to finding a site for the UK radioactive waste geological disposal facility (GDF), the UK government has indicated that it will provide significant additional community investment (a new term for CBAs) to help to maximize the significant economic benefits that are inherent in hosting a nationally significant infrastructure project, and in the community 'providing such an essential service to the nation' (DECC 2014b). The investment is seen as additional to the investment and jobs that a major infrastructure project of this kind will bring to an area. It is also additional to any agreements between the developer and communities to mitigate impacts during construction, for example, under Section 106 of the Town and Country Planning Act (TCPA) 1990.

\section{Some concluding points on a fuzzy area}

As can be seen, justification for CBAs varies considerably, between countries, project types and over time. In the context of UK major energy projects, the argument here is for a much tighter set of justifications than for those referred to in the US examples.

Compared with many other forms of development (eg new housing or retail facilities), the benefits of large energy projects tend to be less concentrated in the local area and may be contributing to national objectives (eg on security of supply, $\mathrm{CO}_{2}$ reductions, and climate change policy). Such contributions to national policy objectives may of course also be the case, or at least partly the case, for other large projects including strategic transport projects (roads, rail lines and airports), and waste and water supply 
projects, but they are particularly marked for energy projects contributing to a national grid electricity supply system. As such one justification for CBAs is that they are some form of reparation to a host area for taking a major project in the national interest.

A further justification relates to the issue of hard to mitigate local impacts from an energy project. This particularly relates to the construction stage, which for some major energy projects can lead to community disruption for long periods of perhaps up to 10 years, and well beyond that for nuclear waste depositories. Whilst many impacts, such as on local roads and on housing markets can be mitigated, with for example the use of Park and Ride schemes to take commuting workers out of their cars, and purpose built worker campus accommodation to take in-migrant workers out of local housing markets, there can still be difficult to mitigate impacts on local amenity and on community life.

At this point it should also be noted that there is scope for considerable confusion here on the role of CBAs in relation to other planning and management measures, as will be highlighted in the following sections. They are different from project designed-in measures which seek to minimise adverse local impacts at an early stage of planning; they are also different from any subsequent mitigation and enhancement measures which may evolve during the assessment and decision making process, such as the transport and housing measures noted in the previous paragraph. Planning decisions must be based on planning issues and material considerations; these exclude community benefits (ie: planning decisions should not be bought) (see Walter 2012). In England CBAs are also additional to S106 obligations under the 1990 TCPA (Section 75 in Scotland's planning legislation), which may encompass some of the mitigation measures. Recent government guidance on community benefits for wind farms in England (DECC 2014a) reinforces this point:

These community benefits are separate from the planning process and are not relevant to the decision as to whether the planning application for a wind farm should be approved or not - i.e. they are not 'material' to the planning process. This means they should generally not be taken into account by local planning authorities when deciding the outcome of an application for a wind farm.

\section{Scale of benefits}

The scale of benefits of some international energy projects has already been noted and, depending on interpretation, has been quite large --- as for the EDF French nuclear programme. However early examples of community benefits for energy projects in the UK were quite small scale, and somewhat ad hoc. For example the Sizewell B amelioration programme totalled less than $£ 600,000$. In contrast, the recent Hinkley Point $\mathrm{C}$ proposed a substantial £128 million CBA package which is additional to the $£ 100$ million already pledged for infrastructure mitigation and enhancement measures (West Somerset Council 2016). 
The increasing scale, and an attempt to formalise and build in some logic to the scale of benefits, is quite neatly summarised by the recent history of CBAs in relation to Scottish on-shore wind farm activity. Over the last 15 years the scale of benefits has increased from $£ 1000$ per $\mathrm{MW}^{3}$ size of the project over the working lifetime of the project (normally 25 years) for early projects, to at least $£ 5000$ per MW for more recent projects (Natural Scotland, 2014). Thus, for a wind farm of $20 \mathrm{MW}$ the current annual benefit would be at least $£ 100,000$. In 2013 the renewable energy industry also agreed a protocol to provide community benefits in connection with eligible on-shore wind schemes in England of no less than $£ 5000$ per MW per year or benefits in kind to an equivalent value. The annual contribution will be index-linked and will commence within 12 months of the project making first commercial export of power and apply for the operational lifetime of the scheme (RenewableUK 2013).

For large solar energy projects, which are becoming more numerous in the UK, the scale of benefits has been somewhat less than for on-shore wind farms. For example, for the county of Dorset in southern England, community benefit negotiations are based on a minimum benchmark of $£ 1000$ per MW of installed capacity per year for a period of 20 years, index linked to the Retail Price Index (or a pro-rata single upfront community benefit payment). However, there is little current consistency with rates of up to $£ 3000$ per MW for similar projects in Cornwall (Dorset CC 2015). Solar farm host locations are keen to learn from the Scottish on-shore wind farm experience, but are partly hindered by the lack of national guidance on solar farm community benefits.

Of course when the MW scale of a modern nuclear power station, or off-shore wind farm, is factored in the sums can become much larger. At the $3.2 \mathrm{GW}^{3}$ (3200 MW) Hinkley Point $\mathrm{C}$, the annual benefits for the operational station have been agreed at $£ 3.2$ million (ie £1000 per MW), giving a lifetime benefits package of $£ 128$ million (DECC 2013). For off-shore wind farms, many of which are now very large (over $1 \mathrm{GW}$ and rising), the logic is less well developed, perhaps reflecting the out of site out of mind remote off-shore locations, although such projects often have substantial onshore cable routes connecting into sub-stations. Some, predominantly near-shore English wind farms (eg North Hoyle and Rhyll Flats off the north Wales coast) have followed the pattern of the on-shore wind farms, with benefits pro rata to MW size; but in many cases, and for some of the latest large North Sea distant off-shore wind farms, the benefits packages have to date proved to be more ad hoc and pro rata much smaller than for on-shore projects. However a recent $£ 10$ million CBA initiative by the Danish energy company Dong, in relation to its Hornsea One and Race Bank wind farms, is of note; a fund will distribute nearly half a million pounds a year to help local initiatives for each of the next 20 years (Dong 2016). A report by the University of Edinburgh on community benefits from offshore renewables (Rudolf et al 2014), recommends the avoidance of restrictive guidance for the relatively new, developing and risky by nature off-shore renewables industry. 
Other recent examples of the rising scale of benefits in the UK are provided by approaches to the disposal of nuclear waste, and to the exploitation of shale gas (fracking). The UK Nuclear Decommissioning Authority (NDA) provides a Community Fund for each of the communities at Drigg in the Borough of Copeland, West Cumbria, England, and at Dounreay in Caithness, Scotland, both of which have storage facilities for low level nuclear waste. For example, at Drigg, the NDA contribution is an initial amount of $£ 10$ million at the commencement of a project providing an additional disposal vault at a long established facility, plus $£ 1.5$ million each year for the estimated 10 years of operation (NDA 2015). Section 6 of the paper outlines the management of the Copeland Community Fund.

However, in relation to the proposed much larger scale UK high level radioactive waste geological disposal facility (GDF), uncertainty of the nature and scale of community benefits was one of the factors which led Cumbria County Council to reject in 2013 moving to the next stage of the site search process. This led to a government review of its approach to the GDF, including community benefits. In the resultant White Paper (DECC 2014), the Government has committed to significant community investment, comparable to other international GDF projects. It also introduced a multi-stage element to the funding, to support communities that volunteered to engage with the process, and reflecting the long time scale involved in planning and developing such a facility:

Community investment of up to $£ 1 m$ per involved community, per year, will be made available in the early stages of the siting process. This amount of community investment would rise to up to $£ 2.5 \mathrm{~m}$ per year for the community (or communities) that progresses to the stage of intrusive, borehole investigations to assess a potentially suitable site (or sites). This funding would only continue for as long as the community remained engaged in the process.

If and when a final community was chosen, and agreed to be the host location for the GDF, a more substantial CBA package would follow.

A range of community benefits has also been proposed in relation to the potential, and very controversial, introduction of shale gas exploitation in the UK. The benefits include the provision for local councils to keep all business rates paid by developers, and for energy firms to make direct payments to local residents and to set up trust funds to be managed by local communities. The energy industry also announced further community benefits of $£ 100,000$ per well site when a test well is drilled, plus $1 \%$ of the share of revenues from any resultant gas production (Department for Business, Energy and Industrial Strategy, 2016; Finlayson et al 2016).

\section{Types of benefits}


Community benefits for energy projects can come in various forms. A summary listing which applies to many types of energy project, and which was set out in some detail in the 2009 EU COWAM report on the management of radioactive waste, includes the following three broad categories:

- financial incentives: an annual payment or lump sum or both; share in local tax revenues; discounts in terms of reduced utility fees; and equity shareholding or profit sharing with the local community, for example in a renewable energy project or gift shares into the ownership of a local community organisation;

- social benefits in kind where a developer may provide for a community facility or local environmental improvements: a widening range including transport improvements over and above those needed for a development to proceed, affordable housing, training/apprenticeship schemes, village halls, sports facilities, improved telecoms etc; and

- community empowerment measures: with local participation in decision making and/or ongoing monitoring, and local capacity building.

Recent government guidance on community benefits for wind farms in England (DECC 2014a) has a similar listing with two main categories (see Table 1). Social benefits are also increasingly being used to enhance local wellbeing, particularly in relation to actual and perceived health, safety, crime and relative deprivation issues (Chadwick and Glasson 2017). The various types of benefits have their advantages and disadvantages. For example, although lump sum financial incentives may bring immediate benefits for communities, the community may demand more for continued involvement. Annual payments can demonstrate a long term commitment by a developer and allow a community to assess the benefits of participation over time, but they could encourage a community dependency culture. In terms of social benefits in kind, infrastructure improvements have the advantage of being highly visible to the local population, but there may be some local opposition (for example to new transport projects), and they may provide an opportunity for local and central government to cut down on their own investments in the community.

Owning a share in an energy project is another way in which an individual or group can benefit. This approach has been utilised for some renewables projects in the UK; but, with less than $10 \%$ locally owned and more than $90 \%$ owned by the big energy companies, the UK is well behind some EU countries such as Denmark and Germany. In Denmark for example, under the 2008 Renewable Energy Act, developers must offer up to $20 \%$ of shares in a project to individual households living within $4.5 \mathrm{~km}$ radius of the site; any shares not taken up are then offered to other householders in the wider municipality (Meacham 2012). Strachan et al (2015) also note the dominance of major projects and large corporations in the UK, although believe that there is some scope for community renewables via joint ownership. 
The value of community empowerment measures is emphasised by many authors. For example, with regard to the management of radioactive waste, European Commission research (Argona 2010) sees such measures as a way of allowing a community 'to feel a sense of control over the siting, development and even operation of the project'. A very interesting example of community engagement is provided by the activities of the West Cumbria Managing Radioactive Waste Safely partnership in the UK. This was set up to ensure a wide range of community interests were involved in the discussion of issues around the potential siting of a geological disposal facility in West Cumbria (West Cumbria MRWS 2012). Funded by a central government 'engagement package', but with a largely local agency membership independent from central government, the partnership employed a range of public and stakeholder engagement measures to explore public concerns and to get feedback on key issues. One element of the partnership work resulted in the clarification of a set of principles to be applied to any future community benefits agreement, including for example 'any benefits must deliver both short and long-term community well-being for West Cumbria as a whole'; 'the magnitude of benefits must bear a clear relationship to the overall scale, nature and national significance of the development'.

Table 1 here

In practice, there is often an integrated package of measures including several aspects of the various types outlined. Also some constraints may be imposed on the type and mix of benefits. Cass et al (2010) note a strong community preference in many cases for the benefit of cheap energy, but this can be severely constrained by both technical and regulatory obstacles. However, experiences in some other EU countries appear better than in the UK on this measure (Strachan et al, 2010), and there are some UK initiatives (RES 2015). There may be other steers; for example in a toolkit for delivering benefits from wind energy projects, the UK Renewables Advisory Board (2009) advocates benefits which provide gains for the community as a whole, and which are linked to sustainable energy (Table 2). Cowell et al (2012) also note a case for using some of the community benefits from wind farm developments to support local ownership of renewable energy, thereby potentially delivering a higher level of local benefits and local resilience.

Table 2 here

\section{Management of benefits}

How and by whom community benefits are managed in practice can be a contentious issue. Large sums of money over a long timescale can be involved, and issues of fairness and accountability are important. Some researchers (see for example Kojo and Richardson 2013) have drawn attention to a distinction in approach which applies not 
only to the management of benefits, but also to the scale and types involved. A legally imposed approach is one where the scale, type and preconditions of benefits are largely determined beforehand in legislation; in contrast, a locally-negotiated approach involves negotiation between the key players at the local level without a legislative framework, followed by some form of formal agreement between the negotiating parties. Much of the guidance and the toolkits already noted, support a strong role for local negotiation, with developers encouraged to engage openly with local communities to assess their needs, benefits models and potential beneficiary communities. In practice there may also be some combination of approaches, with a framework set by national legislation or guidance, but still with some scope for local negotiation. A framework approach may also be set at a more regional level. It may also be set by the industry itself, as exemplified by the protocol on community benefits developed by Renewable UK ('the voice of wind and marine energy') in 2013 in relation to on-shore wind farms in England of $5 \mathrm{MW}$ and above.

Local negotiation does raise the issue of who represents the community, and the role of local government and local politicians. In practice this can lead to a choice between either working through existing local councils or setting up new organisations, such as a Community Trust Fund, to manage the CBA process. Important here is the degree of community confidence in local politicians and officers to operate impartially, representing all the community and not just the decision making authorities. Cowell et al (2011), from their research in Wales, highlight examples of considerable scepticism of local people with regard to the capacity of local authorities to manage the process in the best interests of the relevant communities. There are pros and cons to the various management models, as set out in Table 3 which relates to a toolkit for wind energy development in the UK (CSE 2009). Where a CBA is managed through the local authority, there may be merit in the use of a role such as a local authority Developer Contributions Officer, which is clearly separate from the local authority planning function. It is also reasonable to assume that developers will have an interest as to how the funds they are providing are being managed.

\section{Table 3 here}

An example of a management approach is provided by the previously noted Copeland Community Fund (CCF), which was established in 2008 in relation to the storage of low level radioactive waste near the village of Drigg in West Cumbria. The Fund is managed by a Project Board, set up under a legal agreement between the Nuclear Decommissioning Authority (NDA) and the relevant local authorities. The seven members of the board are: the Leader and Opposition Leader of Copeland local authority (host area), two members of Cumbria County Council (host region), one member of the NDA (fund provider) and two independent members (appointed after 
public invitation). The objectives of the CCF are to make grants and loans and to support activities which promote the social, economic and environmental wellbeing of the inhabitants and area of Copeland. Likely projects for support include employment, education and skills, economic and social infrastructure and economic diversification (NDA 2015).

\section{Distribution of benefits}

The distribution of community benefits can also be contentious and management bodies need to operate in a fair and transparent way. A key issue is what is the relevant community? Walker (2011) sets out a range of ways in which this appealing term of 'community' has been defined in relation to carbon reduction projects. These include: actor, scale of activity, spatial setting, form of network, and a type of process through which carbon reduction objectives can be implemented. In practice, there may be some combination of the various approaches to those criteria to be used in relation to identifying the community for benefits distribution, and also for involvement in the management of the process. These can include, for example: proximity to the development, the degree of received nuisance such as visual impacts (including identification of Zones of Theoretical Visibility [ZTVs] which may not always be directly related to distance) and from construction stage traffic, and local population density. Applying information on such criteria may not be straightforward and simpler administrative solutions might be used relating to local authority areas. For example, where development impacts straddle several authority areas, then benefits may be allocated amongst them perhaps on a population pro rata basis. The complexity in defining 'community' and indeed 'stakeholders' in an offshore context, in comparison with the onshore context, should be noted in particular and this might partly explain the still limited application of a CBA approach for offshore wind projects.

However a predisposition in favour of a local distribution of benefits may be contentious in many ways, especially where the development has associated linear infrastructure, such as power lines and rail links. It may also be contentious in terms of perceived equity of opportunity to benefit from major energy projects. Multiple models have been used for splitting payments between local and wider areas for on-shore wind farms in Scotland (Highland Council 2014; Meacham 2012, and Scottish and Southern Energy 2012). The Highland Council also includes a policy variation for off-shore wind, with $20 \%$ of the benefit realised going to coastal communities, and the remaining $80 \%$ going to a Highland Trust Fund.

A particularly interesting case of a distribution approach is provided by Dumfries and Galloway Regional Council in SW Scotland. In 2005 the Council agreed a Wind Farms 
Community Benefit Governance Framework which, amongst other things, established a two tier approach to the distribution of benefits. Under the governance framework:

$60 \%$ of the Community Benefit funds from any one wind farm go to the $15 \mathrm{~km}$ communities (within $15 \mathrm{~km}$ of outer edge of the wind farm) and $40 \%$ will go into a regionwide fund ring-fenced for renewable energy or energy efficiency projects. This fund can be bid into by any Community Council. The $40 \%$ region-wide fund is designed to ensure that some of the funding is spread to as many communities as possible, to give impetus to the national drive towards better energy efficiency and greater use of renewables as an energy source. The $40 \%$ fund is also in-line with developers' wishes to target spend towards renewables and energy efficiency and therefore its existence and use may advantage further funding from developers for communities developing suitable projects (Dumfries and Galloway Council 2005).

The local/regional mix was subsequently amended to 50:50 (Dumfries and Galloway Regional Council 2011). But the policy was nothing but controversial with those communities hosting wind farms seeing the $50 \%$ regional fund contribution being taken away from them, leading to a sometimes adversarial situation between the communities and the Regional Council. The outcome was that in 2015 the Council in its Draft Updated Windfarm Community Benefit Guidelines (Dumfries and Galloway Regional Council 2015) proposed the removal of the 50:50 split and the $15 \mathrm{~km}$ measurement of host communities. It did also propose the retention of a region-wide fund but only to handle any voluntary payments made by developers or communities. In similar vein to this Scottish example, Cowell et al (2011) note for their Welsh study that 'in general, any redistribution of community benefits was seen as diluting the prime function of community benefits which was to atone for the impacts on the nearest communities.'

The contentious nature of distribution has also been highlighted in England with the recent debate on payments to communities where fracking for shale gas may take place. Official policy on community benefits is set out in a Department for Business, Energy and Industrial Strategy document (DBEIS 2016) as noted in section 4 above. It is amplified in an industry publication by the UK Onshore Operators Group (UKOOG 2016), which also advocates a two-tier approach for some of the community benefits, with $1 \%$ of revenues at production stage allocated approximately $2 / 3 \mathrm{rd}$ to the local community and $1 / 3 \mathrm{rd}$ at the county level. Issues of distributive justice associated with this proposed approach are set out by Cotton (2016); for example would individuals in a rural authority receive much higher per capita benefits than those in more densely populated urban/peri-urban communities? Research by Szolucha (2015) on the case of potential fracking in Lancashire noted, amongst many other local concerns, that compensation to landowners was viewed as a way to "overcome local resistance and could potentially constitute a socially divisive conduct by the company". 
Another issue on distribution relates to when benefits are distributed. This partly relates to the timing of any agreement on community benefits. Early agreement on the nature of community benefits in the planning and decision making process may be helpful in terms of providing the community with early benefits. However it also runs the risk of being perceived as an element in the decision (i.e. buying planning permission). As such some commentators advise that the timing of agreements, and any associated distribution of benefits, should follow the decision on the planning permission. There may also be merits in the staging of payments, perhaps related to project milestones, as noted earlier.

\section{Conclusions}

Community benefit agreements have grown in significance over the last 15 years in relation to UK energy projects. On-shore wind projects pioneered many of the approaches to the key issues discussed in this article. But the scope of relevant energy projects is much wider than on-shore wind. There is the growing phenomenon of offshore wind, with projects often on a much larger scale than on-shore, plus other renewables including solar arrays, and emerging technologies such as tidal barrages and tidal streaming. In addition there are fossil-fuelled projects (most recently CCGT), new nuclear build and nuclear waste disposal, and the proposals for the fracking of shale gas. The CBA approach is progressing in most of these areas; it is likely that it is here to stay and widen in coverage to other energy project types, including the new technologies. Government does appear to be committed to making community benefits a norm across all energy technologies.

On-shore wind has provided useful models for CBAs in the wider energy sector, in relation to size, type, management and distribution of community benefits. There is also now much good practice guidance available for on-shore wind, including a move to some formalisation of approaches with regard to the issues raised. Ironically this comes at a time when, at least for England, there is declining government policy support for onshore wind projects. Other energy sub-sectors can and do draw on this evolving practice. For smaller projects, including on-shore wind farms and solar arrays, there may also be some shift in the mix of benefits, with some move away from financial payments towards shared ownership and cheaper fuel tariffs (Dorset CC 2015). For example, Renewable Energy Systems (RES) is introducing local electricity discount schemes (LEDs) for some Scottish Wind farms (RES 2015).

However, the scale of some of the major projects now coming through, including those for nuclear power generation, nuclear waste disposal, and off-shore wind, raises some comparative issues, for example about the scale of benefits and about management models. Distributional equity arguments might suggest the case for an even-handed, more formalised, approach across energy sub-sectors, and there are rising expectations 
by communities about what might be appropriate. On the other hand developers, especially in new technology areas, argue for more flexibility in the nature of CBAs to allow for the technical and policy vagaries associated with bringing new projects to market (Rudolf et al 2014).

Community benefits are often very sensitive issues in communities. Perspectives on such benefits vary; for some they are bribes to take forward a project, unwanted for various reasons, while for others they are an appropriate sharing in the rewards of a development, and provide appropriate reparations. Community understanding can be aided by good practice guidance, representative management and fair distribution in the CBA process. Good guidance emphasises community empowerment in a flexible CBA process, as illustrated for example in the partnership approaches used in relation to nuclear waste management in West Cumbria. This is also generally welcomed by developers, although the very formalisation of the guidance can potentially constrain such empowerment and flexibility. Overall however, as noted by Cass et al (2010), reinforced by Walter (2012), planning decisions linked to localised benefits are intrinsically sensitive and political, and are likely to continue so.

The discussion on justification also highlights the need to be clear on the relationship of CBAs with environmental assessment procedures and the planning process. CBAs are separate to the normal project impact mitigation and enhancement measures associated with the environmental assessment of projects. They are also outwith planning decisions, which must be based on planning issues and material considerations. As noted, CBAs are also additional to S106 obligations under the 1990 TCPA. Research suggests that these distinctions are not always clear to the various participants involved in the process (Cass et al 2010; Cowell et al 2011), and it is a 'shadowy area' (CSE 2005).

The paper has highlighted a number of issues, which contribute to a continuing fuzziness, certainly for energy projects in the UK. Whilst the conclusion is that CBAs are likely to be here for the foreseeable future, they do need to be handled sensitively and with some flexibility across the various energy technologies.

\section{Acknowledgements}

An earlier version of this paper was presented at the Annual UK Planning Schools Research Conference held at Oxford Brookes University in September 2014. The author is grateful to the audience for their comments at the conference. The comments of two referees are also very gratefully acknowledged.

\section{Notes}

1 Environmental Impact Assessment (EIA), Social Impact Assessment (SIA), Strategic Environmental Assessment (SEA), Sustainability Appraisal (SA), Health Impacts Assessment 
(HIA), Habitats Regulation Assessment (HRA), Equality Impact Assessment (EqIA) ---and many more.

2 This abbreviation is useful and used, but the reader should avoid confusion with Cost Benefit Analysis!

31 Megawatt (MW) equals 1,000 Kilowatts (KW). 1 Gigawatt (GW) equals 1,000 MW.

\section{References}

Aitken M, 2010. Wind power and community benefits: challenges and opportunities. Energy Policy, 38:10, 6066-6075

Argona (Arenas for Risk Governance); authors-Kojo M and Richardson P, 2010. The role of compensation in nuclear waste facility siting: a literature review and real life examples (Deliverable 16b; Contract Number FP6 -036413). European Commission: Brussels.

Baxamusa M, 2008. Empowering Communities through Deliberation: The Model of Community Benefits Agreements. Journal of Planning Education and Research, 27; 261-276.

Been V, 2010. Community Benefits Agreements: A New Local Government Tool or Another Variation on the Exactions Theme? Working Paper 2010. Furman Centre for Real Estate and Urban Policy, New York University: New York.

Cass N, Walker G, and Devine-Wright P, 2010. Good Neighbours, Public Relations and Bribes: The Politics and Perceptions of Community Benefits Provision in Renewable Energy Development in the UK. Journal of Environmental Policy and Planning, 12:3, 255-275.

Centre for Sustainable Energy (CSE), 2005. Community Benefits from Wind Power: A study of UK practice and comparison with leading European countries. CSE for Renewables Advisory Board and DTI: London.

CSE, 2007. Delivering community benefits from wind energy development: $A$ Toolkit. Report to Renewables Advisory Board and UK Department of Trade and Industry.

CSE, 2009. Delivering community benefits from wind energy development: $A$ Toolkit. Report to Renewables Advisory Board.

Chadwick A and Glasson J (2017). Social Impacts. Chapter 14 in Therivel R and Wood G (eds) Methods in EIA; 4th Edition. Routledge: Abingdon.

City of Salem, 2014. Community Benefits Agreement: Footprint Power's 674 MW gas-fired power plant project in Salem Harbor. City of Salem website: Massachusetts, USA.

Cotton M, 2016. Fair fracking? Ethics and environmental justice in UK shale gas policy and planning. Pre-print version of paper accepted to Local Environment.

COWAM, main author, Richardson P, 2009. Cowam in Practice: Community Benefits and Support Packages (Report D3, Research Briefs 2; Contract Number FP6/036455). European Commission: Brussels. 
Cowell R, Bristow G, and Munday M, 2011. Acceptance, acceptability and environmental justice: the role of community benefits in wind energy development, Journal of Environmental Planning and Management, 54:4, 539-557.

Cowell R, Bristow G, and Munday M (2012). Wind Energy and Justice for Disadvantaged Communities, Viewpoint produced for the Joseph Rowntree Foundation. JRF: York.

Department for Business, Energy and Industrial Strategy (DBEIS), 2016. Guidance on fracking: developing shale oil and gas in the UK. DBEIS website.

Department of Communities and Local Government (DCLG), 2015. Planning Performance Agreements. DCLG website.

Department of Energy and Climate Change (DECC), 2016. Communities to Benefit from Hosting Nuclear Power Stations, Press Release, 13 July 2016. DECC: London

DECC, 2014a. Community Benefits from On-shore Wind Developments: Best Practice Guidance for England. DECC: London

DECC, 2014b. Implementing Geological Disposal: A Framework for the long-term management of higher active radioactive waste. DECC: London.

Dong Energy, 2016. New $£ 10$ million fund opens to public consultation. Dong Energy website (September 2016).

Dorset CC, 2015. Community Benefits From Solar Farms in Dorset. Dorset CC: Dorchester.

Dumfries and Galloway Regional Council (DGRC), 2005. Dumfries and Galloway Council Wind Farms Community Benefits Governance Framework. Planning and Environment Committee. DGRC: Dumfries.

DGRC, 2011. Review of Community Benefits from Wind Farms. Planning, Housing and Environment Services Committee. DGRC: Dumfries.

DGRC, 2015. Proposed Dumfries and Galloway Council's Wind Farm Community Benefit Guidelines. DGRC: Dumfries.

Finlayson H, Ares E, Smith L, and Keep M, 2016. Shale Gas and Fracking. Parliamentary Briefing Paper 6073, September 2016. House of Commons Library: London.

Glasson J, 2005. 'Better monitoring for better impact management: the local socio-economic impacts of constructing Sizewell B nuclear power station. Impact Assessment and Project Appraisal, 23:3, 215-226.

Gross J, LeRoy G, and Janis-Aparicio M, 2002.Community Benefits Agreements: Making Development Projects Accountable. Good Jobs First: Washington DC.

Highland Council, 2014. Community Benefit Policy. Highland Council: Inverness.

HMG, 2008. Planning Act 2008. London: Stationery Office. 
Kojo M, and Richardson P, J 2013. The Use of Legally-Imposed and Locally-Negotiated Incentive Approaches in the Siting of Nuclear Waste Management Facilities: Comparing Stakeholders' Views in the Czech Republic, Poland and Slovenia. Waste Management 2013 Conference: Phoenix, Arizona.

Meacham T, 2012. Scottish Parliament Information Centre (SPICe) Briefing: Renewable Energy-Community Benefit and Ownership. SPICe, Scottish Government: Edinburgh

Natural Scotland, 2014. Scottish Government Good Practice Principles for Community Benefits from On-shore Renewable Energy Projects. Scottish Government: Edinburgh.

Nuclear Decommissioning Authority (NDA), 2015. The Copeland Community Fund: Annual Report 2014/15 (including 5-year review). NDA, Copeland Borough Council, Cumbria County Council: Copeland Community Fund.

Planning Inspectorate (PINS), 2012-2017. National Infrastructure Planning Advice Notes; in particular Advice Note 8 (2017): Overview of the nationally significant infrastructure planning process for members of the public and others. PINS: Bristol.

Renewable Energy Systems (RES), 2015. RES Local Electricity Discount Scheme (LEDs). RES website (accessed September 2016)

RenewableUK, 2013.On-shore Wind: Our Community Commitment. RenewableUK: London.

Richardson P J, 2010. Community Benefits and Geological Disposal: An International Review. Galson Sciences Ltd: Oakham.

Rudolf D, Haggett C, and Aitken M, 2014.Community Benefits from Off-shore Renewables: Good Practice Review. climateXchange, University of Edinburgh: Edinburgh.

Scottish and Southern Energy, 2012.SSE community investment policy in Great Britain. SSE: Perth.

Strachan P, Toke D and Lal D, 2010. Wind Power and Power Politics: International Perspectives. Routledge: Abingdon.

Strachan P, Cowell R, Ellis G, Sherry-Brennan F and Toke D (2015). Promoting community renewable energy in a corporate energy world. Sustainable Development 23:2, 96-109.

Szolucha A 2015. Fracturing democracy? State, fracking and local power in Lancashire. openDemocracy.net.

United Kingdom Onshore Operations Group (UKOOG) 2016. Community Engagement Charter: Oil and Gas from Unconventional Reservoirs. UKOOG.

Walker G, and Cass N, 2007. Carbon reduction, 'the public' and renewable energy: Engaging with socio-technical configurations. Area, 39:4, 458-469.

Walker G, 2011. The role for 'community' in carbon governance. Wiley Interdisciplinary Reviews: Climate Change. 2:5. 77-82. 
Walter, C. (2012). Incentives-based planning policy: a clash of rationalities. Journal of Environment and Planning Law, 6, 647-657.

West Cumbria MRWS (2012). The Final Report of the West Cumbria Managing Radioactive Waste Safely partnership. West Cumbria MRWS Partnership: Copeland Borough Council.

West Somerset Council (WSC) 2016. Hinkley Point C: Community Impacts Mitigation Strategy. WSC: Wiliton. 